\title{
Fibre optic monitoring of a deep circular excavation
}

1 Tina Schwamb Dipl.-Ing. (FH), MSc, MRes PhD Candidate, Department of Engineering, University of Cambridge, UK

2 Kenichi Soga PhD, FICE

Professor of Civil Engineering, Department of Engineering, University of Cambridge, UK

3 Robert J. Mair CBE, FREng, FICE, FRS

Sir Kirby Laing Professor of Civil and Environmental Engineering, Department of Engineering, University of Cambridge, UK
4 Mohammed Z. E. B. Elshafie PhD

Lecturer, Laing O'Rourke Centre for Construction Engineering and Technology, Department of Engineering, University of Cambridge, UK

5 Richard Sutherden BEng(Hons), CEng, FICE Technical Director, AECOM, UK; Design Manager Lee Tunnel Project Management Team, UK

6 Clotilde Boquet MEng

Civil Engineer, Bachy Soletanche Ltd, Camberley, UK

7 John Greenwood BSC(Hons), CEng, MICE Senior Technical Consultant for Thames Tideway Tunnels, J G Engineering Consultancy Ltd, London, UK
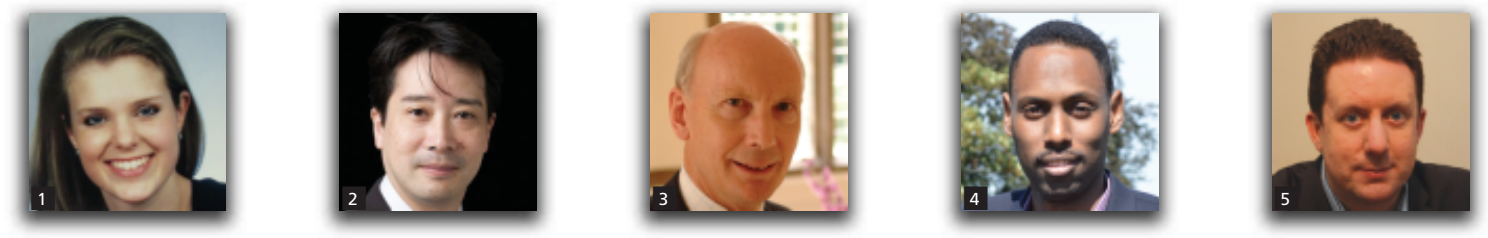
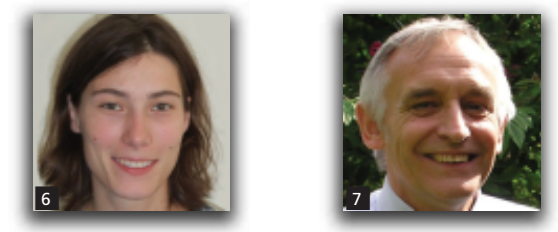

This paper describes part of the monitoring undertaken at Abbey Mills shaft $F$, one of the main shafts of Thames Water's Lee tunnel project in London, UK. This shaft, with an external diameter of $30 \mathrm{~m}$ and $73 \mathrm{~m}$ deep, is one of the largest ever constructed in the UK and consequently penetrates layered and challenging ground conditions (Terrace Gravel, London Clay, Lambeth Group, Thanet Sand Formation, Chalk Formation). Three out of the twenty $1.2 \mathrm{~m}$ thick and $84 \mathrm{~m}$ deep diaphragm wall panels were equipped with fibre optic instrumentation. Bending and circumferential hoop strains were measured using Brillouin optical time-domain reflectometry and analysis technologies. These measurements showed that the overall radial movement of the wall was very small. Prior to excavation during a dewatering trial, the shaft may have experienced three-dimensional deformation due to differential water pressures. During excavation, the measured hoop and bending strains of the wall in the chalk exceeded the predictions. This appears to be related to the verticality tolerances of the diaphragm wall and lower circumferential hoop stiffness of the diaphragm walls at deep depths. The findings from this case study provide valuable information for future deep shafts in London.

\section{Notation}

$c^{\prime} \quad$ cohesion intercept

$c_{\mathrm{u}} \quad$ undrained shear strength

D average shaft diameter

$d \quad$ distance between excavation and soil face fibre optic cables

$E \quad$ short-term Young's modulus of diaphragm wall

$E^{\prime} \quad$ drained Young's modulus of ground layers

$E_{\mathrm{u}} \quad$ undrained Young's modulus of ground layers

EI flexural stiffness of diaphragm wall
$K_{0} \quad$ lateral earth pressure coefficient at rest

$K_{\mathrm{a}} \quad$ lateral earth pressure coefficient under active conditions median radius of shaft diaphragm wall thickness effective diaphragm wall thickness initial water pressure decreased water pressure variable length of cable variable wall depth factor considering thermal expansion coefficients 
bulk density of ground layers

$\Delta p_{\mathrm{i}} \quad$ incremental lateral pressure on inside of shaft

$\Delta p_{0} \quad$ incremental lateral pressure on outside of shaft

$\Delta \varepsilon \quad$ incremental mechanically induced strain

$\Delta \varepsilon^{\prime} \quad$ incremental strain

$\Delta \varepsilon_{\mathrm{e}} \quad$ incremental mechanically induced strain on excavation face

$\Delta \varepsilon_{\mathrm{s}} \quad$ incremental mechanically induced strain on soil face

$\Delta \varepsilon_{\mathrm{t}} \quad$ incremental temperature-induced strain

$\Delta \varepsilon_{\theta} \quad$ incremental circumferential hoop strain

$\Delta \kappa \quad$ incremental curvature

$\Delta \sigma_{\mathrm{r}} \quad$ incremental radial stress

$\Delta \sigma_{\theta} \quad$ incremental circumferential stress

$\varepsilon_{\mathrm{p}} \quad$ pre-tension of fibre optic cables

$v$ Poisson's ratio

$\sigma_{\mathrm{h}} \quad$ total horizontal in situ stress

$\sigma_{\mathrm{v}} \quad$ total vertical in situ stress

$\phi^{\prime} \quad$ effective stress friction angle

\section{Introduction}

Thames Water Utilities Ltd, the largest water and wastewater service company in the UK, has developed a number of major engineering schemes, one of which is the Lee tunnel project. The $7.2 \mathrm{~m}$ diameter Lee tunnel, running $6.9 \mathrm{~km}$ from Abbey Mills pumping station (AM) to the Beckton treatment works in east London, requires the formation of four large-diameter shafts. These are some of the largest ever constructed in the UK. This paper presents the details of a case study conducted at AM. The shaft has an external diameter of $30 \mathrm{~m}$, and was constructed using diaphragm walls $84 \mathrm{~m}$ long and $1.2 \mathrm{~m}$ thick. The final excavation depth was $73 \mathrm{~m}$, and as a result the shaft had to pass through mixed and challenging ground conditions (Figure 1(a)).

This major construction project provided the opportunity for a large and ambitious instrumentation scheme including, among others, fibre optic (FO) sensors. In this study the Brillouin optical time-domain reflectometry/analysis (BOTDR/A) technologies (Omnisens, 2013; Yokogawa, 2005) were applied, which provide continuous strain measurements along an FO cable embedded in the diaphragm wall.

FO instrumentation was installed in three panels of the diaphragm wall that constituted the primary lining of the shaft (Figure 1(b)). Embedding FO instrumentation in such a deep wall and configuring the instrumentation to measure bending and hoop response has never been tried before. The instrumentation was designed to enable the bending strain to be determined, as well as the circumferential hoop strain of the wall prior to and during shaft

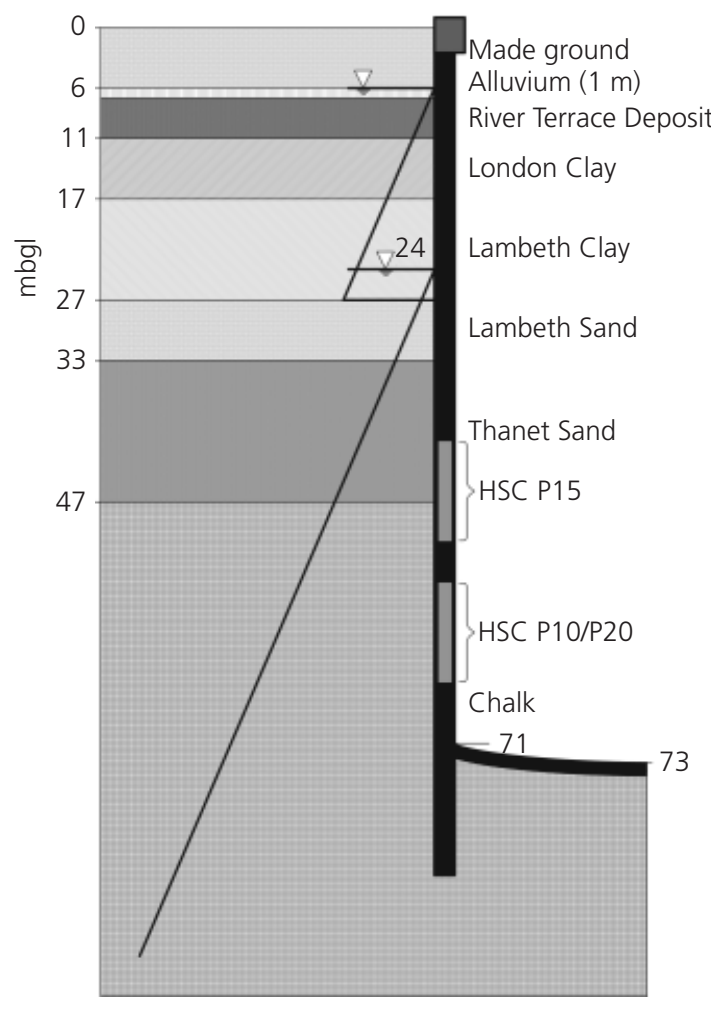

(a)

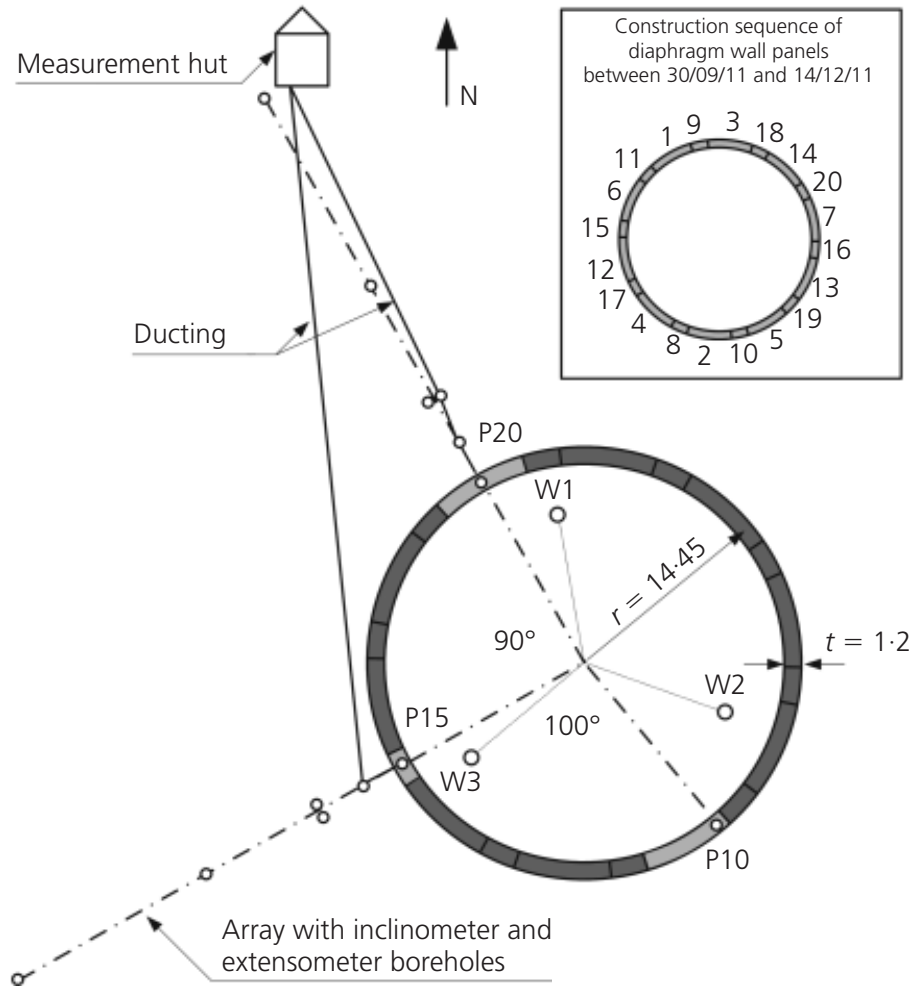

(b)

Figure 1. AM pumping shaft: (a) stratigraphy and water pressure distribution; (b) plan view with instrumentation overview, dewatering wells and panel construction sequence 
excavation. The hoop strain measurements allow back-calculation of the lateral earth pressure acting on the shaft wall.

Monitoring of construction projects yields valuable information on the performance of the structures, which can be used to backanalyse the design. The construction of the AM shaft provided a unique opportunity to understand the bending and hoop response of these diaphragm walls, which will be very valuable for the design of future similar shafts, including those on the Thames Tideway Tunnel project, which is currently undergoing public consultation.

\section{Principle of fibre optic sensing}

The BOTDR and BOTDA techniques can measure the continuous strain profile along the length of an FO cable; this is a clear advantage over point sensors. Both are based on Brillouin scattering: when an optical pulse travels along a fibre a frequency-shifted component, the Brillouin component, is backreflected. The frequency shift is linearly proportional to strain (Mohamad et al., 2010), induced mechanically or by a temperature change. If only mechanical strain is of interest, as in this application, the temperature effect has to be compensated for. This is usually done by installing a loose-tube FO cable in parallel to the strain-sensing fibre. The fibres in the loose-tube cable swim in a liquid gel, and are therefore not affected by structural movement. For the strain-sensing fibre, the reinforced FO cable manufactured by Fujikura Ltd is used. To resist the harsh environment, this cable has four glass cores protected by a thick nylon sheath, and is strengthened by two steel wires.

The BOTDR technology relies on spontaneous backscattering, whereas BOTDA stimulates the backscattered signal, which enhances the accuracy and resolution of the output signal. The trade-off is that BOTDA requires both ends of an intact FO cable to be connected to the read-out unit, and hence cannot be used if the cable has experienced a breakage, which can occasionally happen. In the case of a single breakage along the cable, the BOTDR technology can still be used to interrogate the FO cable from both ends.

At AM both read-out units, BOTDR and BOTDA, were used, as some cables experienced damage and hence ruled out use of the BOTDA unit.

\section{Installation of fibre optic instrumentation}

Three panels were instrumented with FO instrumentation (Figure 1(b)). Panel P15 was a secondary panel, $2.8 \mathrm{~m}$ wide, with one rectangular reinforcement cage. Panels P10 and P20 were $6.5 \mathrm{~m}$ wide primary panels consisting of three trapezoidal reinforcement cages, approximately $1.6 \mathrm{~m}$ wide, next to each other. Each $84 \mathrm{~m}$ long reinforcement cage was split into six pieces.

One reinforcement cage per panel was instrumented with three FO cables: the bending strain cable (BSC) to measure the bending strain along the entire depth of the wall; the hoop strain cable (HSC) to measure the hoop strain at predefined locations; and the loose-tube temperature cable (TC), which is used for temperature compensation.

Figure 2 schematically shows the arrangements of the three FO cables on one reinforcement cage (for clarity it is shown in two separate drawings). The BSC was pre-tensioned in sections over the length of the wall to enable compression to be measured. The TC was installed in parallel to the BSC without pre-tension. The eight horizontal sections in the hoop direction of the HSC also required pre-tension.

The instrumentation process was conducted in two stages. The first stage was carried out while the cages were lying on the ground. In the second stage, when the six pieces were lowered into the trench and spliced together, the FO cables were attached to the subsequent pieces bridging over the cage splices.

\subsection{First installation stage}

The first stage of the FO installation was carried out while the cages were stored on site, before their subsequent installation. The BSC and TC were attached to the bottom piece (piece A). The remaining length of cable needed during the second installation stage was coiled on cable drums, which were temporarily fixed to the top of piece A. The BSC was attached with special clamps (Figure 3), and pre-tensioned to $\varepsilon_{\mathrm{p}} \approx 2000 \mu \varepsilon$; the TC was loosely fixed with cable ties.

The HSC of panels P10 and P20 were attached to the second piece of the cage from the bottom (piece B), where the hoop stresses were expected to be largest. For panel P15 the third piece of the cage from the bottom (piece C) had to be used, because of the future tunnel opening. The special clamps (Figure 3) were used to pre-tension the eight hoop measurement sections to $\varepsilon_{\mathrm{p}} \approx 2500 \mu \varepsilon$.

Figure 3 shows a photograph of the pre-tension plastic clamp, which is specially designed to accommodate and clamp the strain-sensing FO cable tightly. The clamp is placed into a stainless steel seat that is welded to the reinforcement cage beforehand. Pre-tension can then be achieved by tightening or loosening the nuts as required.

\subsection{Second installation stage}

After the diaphragm wall trenches had been excavated, the instrumented piece A was placed in the bentonite-supported trench. When the top of the piece reached ground level, the cable drums with the BSC and TC were taken off and placed on cabledrum stands. After the splice of piece B to piece A, the cages were lowered into the trench, and the BSC and TC could gradually unroll from the drums. When the top of piece B reached ground level, the HSC drums were then taken off and placed on the cable-drum stands. Subsequently, the four remaining pieces $\mathrm{C}-\mathrm{F}$ were spliced to the cage, one at a time. The TC 
Fibre optic monitoring of a deep circular excavation

Schwamb, Soga, Mair et al.

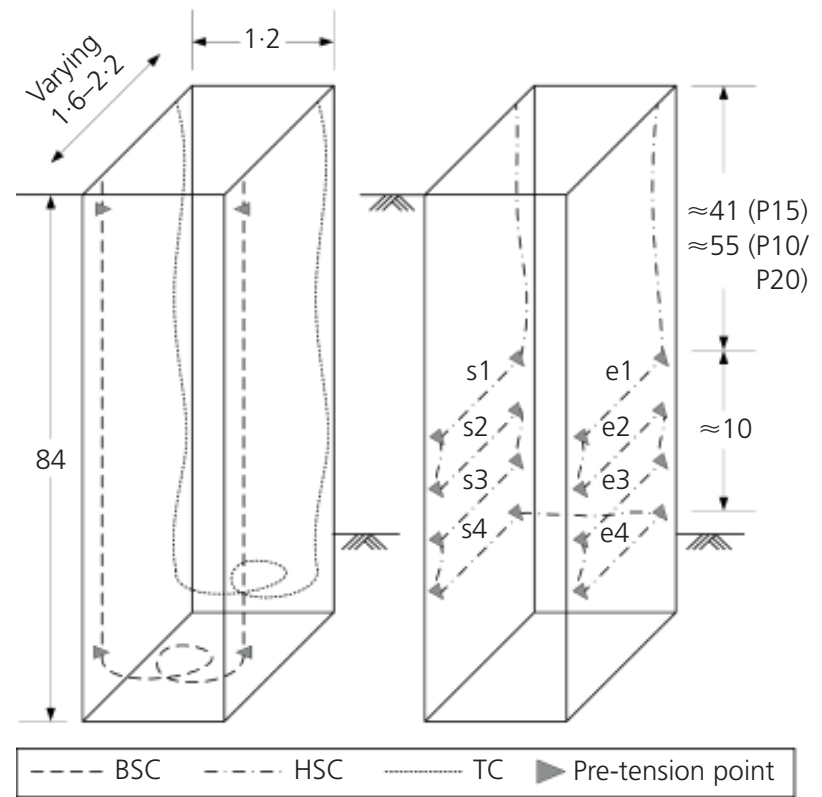

(a)

(b)

Figure 2. Schematic of FO cable arrangement on the same reinforcement cage: (a) BSC and TC; (b) HSC (all dimensions in m)

and HSC were attached loosely to the longitudinal reinforcement bars using cable ties, whereas the BSC was pre-tensioned using the special clamps (Figure 3 ) at the top of each piece.

At the top of the last piece of the reinforcement cage (piece F), the FO cables were threaded through a steel pipe, which protected the cables when the top of the concrete was broken off and prepared for the construction of the capping beam. When all the panels and the capping beam had been constructed, all FO cables were routed to a safe and clean working environment through ducting, shown in Figure 1(b).

\subsection{Breakages}

The measures taken to avoid breakages of the FO cables during both the planning and construction stages were generally effective, although some of the cables experienced damage during their installation and during shaft excavation.

The BSC of panels P10 and P15 experienced one breakage or large bend each towards the toe of the wall, which happened during installation of the wall. The measured loss of pre-tension at panel P10 suggests that the cable snapped while it was being lowered into the trench. The reason for the breakage at panel P15 is not clear.

Further breakages of the BSC on the excavation face happened during shaft excavation. The cables, which theoretically had been installed with $50 \mathrm{~mm}$ concrete cover, were in some locations

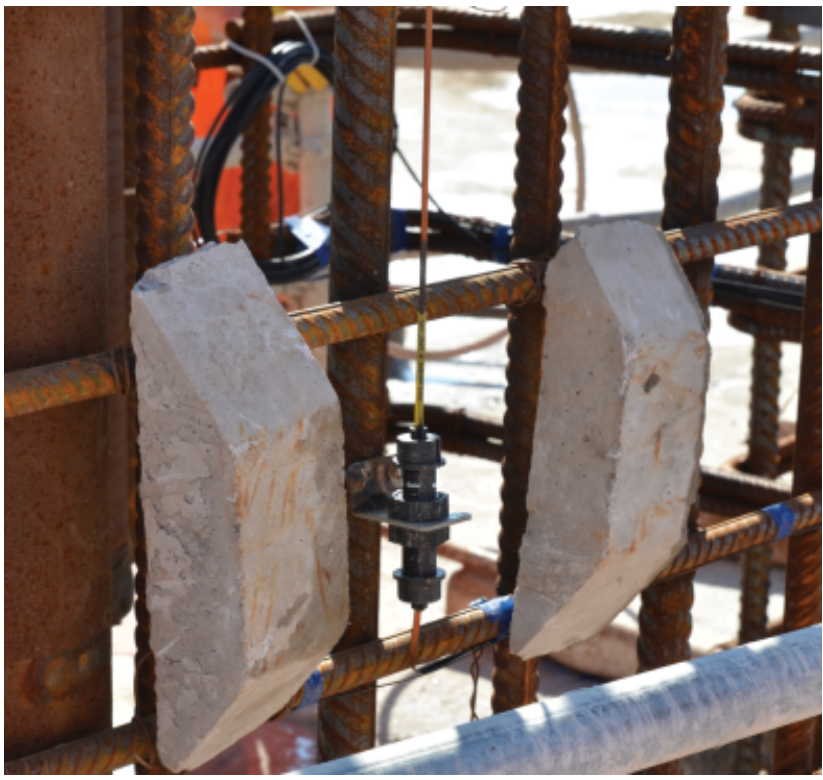

Figure 3. Pre-tension clamp to attach strain-sensing FO cable to reinforcement

pushed closer to the concrete-soil interface during concreting of the wall. During excavation the excavator bucket scraped the diaphragm and the wall was high-pressure jet-washed. This damaged some of the BSC. The problem was recognised early, and more care was taken around the locations of the cables.

The cables with one breakage were not repaired, as the BOTDR read-out unit could be used to obtain data from both ends of the cable up to the breakage. Those cables with two breakages were repaired, recovering most of the data.

\section{Monitoring}

Approximately 1 month after construction of the diaphragm wall was complete (14 December 2011), strain measurements from the FO cables were taken in January and February 2012 before and during a dewatering trial. In this dewatering trial three $75 \mathrm{~m}$ deep wells were drilled inside the yet-to-be-excavated shaft, and the water level from the deeper aquifer was lowered from $24 \mathrm{~m}$ to $70 \mathrm{~m}$ below ground level (bgl) to test the groundwater cut-off of the diaphragm walls, and the in situ permeability characteristics of the chalk.

Excavation of the $73 \mathrm{~m}$ deep shaft started in April 2012, and was completed in September 2012. Baseline measurements from the FO cables were taken at the end of March, after which measurements were taken at the following excavation depths: 9, 15, 21, $35,47,53,62$ and $71 \mathrm{mbgl}$.

For the dewatering trial only BOTDR was used. During the excavation monitoring both BOTDR and BOTDA were used to 
take readings, depending on whether the cables had experienced any damage.

\section{Data analysis}

\subsection{Hoop strain}

On each site visit, a minimum of three readings were taken from each cable. Those readings were averaged to obtain one strain profile for each excavation depth, which is subsequently called a 'dataset'. The strain profile of the HSC exhibits eight peaks corresponding to the pre-tensioned measurement locations (Figure 2(b)). A change of strain in these sections indicates compression or tension in the hoop direction. A close-up view into one of these peaks is presented in Figure 4. The averaged readings of different datasets are displayed, as well as the applied pre-tension and a schematic of the cable arrangement. The applied pretension should appear as a step strain change; however, the output data show a smooth strain curve. This is due to the spatial resolution of the read-out unit, which averages the strain measurements over a distance of $1 \mathrm{~m}$. This is also the reason why the real change in hoop strain can be quantified only by taking the average differences between the baseline and subsequent datasets in a $250 \mathrm{~mm}$ wide interval around the centre of the peak, as indicated by the grey box in Figure 4. This measured incremental strain, $\Delta \varepsilon^{\prime}$, then needs to be compensated for temperatureinduced strain. The incremental mechanically induced strain $\Delta \varepsilon$ is isolated according to

1. $\Delta \varepsilon=\Delta \varepsilon^{\prime}-\alpha \Delta \varepsilon_{\mathrm{t}}$

where $\Delta \varepsilon_{\mathrm{t}}$ is the measured incremental strain from the TC, and $\alpha$ is a factor taking the different thermal expansion coefficients for concrete and the cable into account, derived from laboratory tests (Mohamad, 2008). In this study the temperature strain, $\Delta \varepsilon_{\mathrm{t}}$, at hoop cable level is within $\pm 40 \mu \varepsilon$.

\subsection{Bending strain}

The averaged datasets were correlated along the cable length axis to compensate for any change in cable length, which could occur, for example, when a new connector was spliced to the FO cable, or an extension cable was used. The difference between each dataset and the previous dataset could be calculated to obtain the change of strain, $\Delta \varepsilon^{\prime}(x)$, along the cable length, $x$. To conduct the temperature compensation, the change in temperature strain, $\Delta \varepsilon_{\mathrm{t}}(x)$, had to be aligned with the strain data. The compensation is conducted according to Equation 1.

To obtain the incremental curvature, $\Delta \kappa(z)$, over the depth of the wall, $z$, the sections along the soil and excavation faces were extracted from $\Delta \varepsilon(x)$ and renamed $\Delta \varepsilon_{\mathrm{s}}(z)$ and $\Delta \varepsilon_{\mathrm{e}}(z)$ respectively. Owing to the induced pre-tension, these sections could easily be identified. The incremental curvature could then be calculated according to

2. $\Delta \kappa=\frac{\Delta \varepsilon_{\mathrm{s}}-\Delta \varepsilon_{\mathrm{e}}}{d}$

where $d$ is the distance between the BSC on the soil and excavation sides. The resulting curvature was then filtered using a low-pass Butterworth filter (Butterworth, 1930). A positive curvature indicates tension on the soil face and compression on the excavation face.

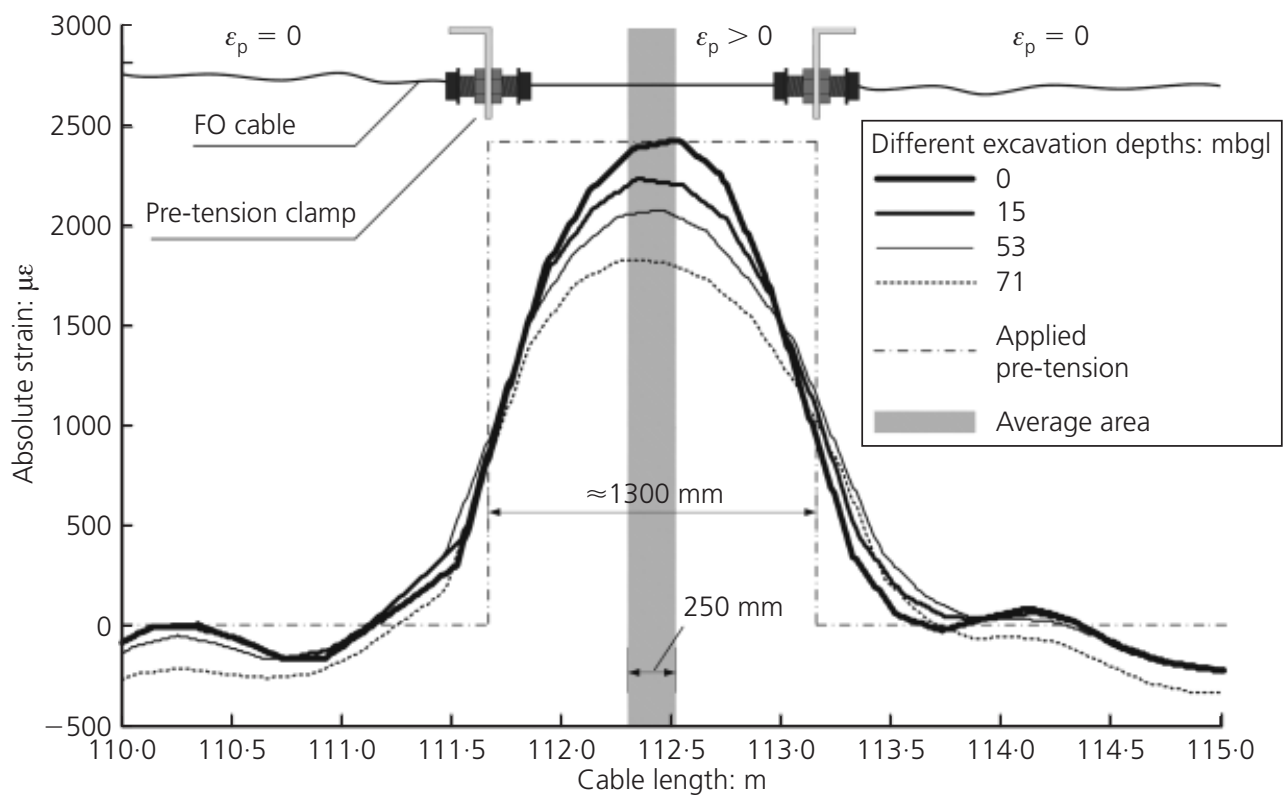

Figure 4. Raw data of pre-tensioned section of HSC at different excavation levels 


\section{Results and discussion}

\subsection{Plaxis design predictions}

The design of the AM shaft was conducted with the finite-element (FE) modelling software package Plaxis (v9.0), which was run in 2D axisymmetric mode. A Mohr-Coulomb soil model without strain-hardening was adopted in the analysis. The input properties are shown in Table 1; these are characteristic design values, to which a partial safety factor of 1.0 is applied (serviceability limit state, SLS, according to BS EN 1997-1:2004 National Annex A; BSI, 2004). The parameters are based on $\operatorname{SPT}(N)$ tests, laboratory investigations, and correlations with published data. For the Thanet Sands, and the unweathered medium to hard, rubbly to blocky chalk (Clayton, 1990), in situ high-pressure dilatometer tests (HPD) were conducted. In combination with previous investigations and empirical correlations, stiffness degradation curves were obtained and used to estimate Young's moduli. An axial strain level of $0 \cdot 1 \%$ was assumed. Installation effects were not modelled directly, but incorporated by reduced $K_{0}$ values of the London Clay and the Lambeth Group (both at $K_{0}=1 \cdot 0$ ).

A concrete mix grade C50/60 with 70\% ground granulated blastfurnace slag (ggbs) was used for the reinforced concrete diaphragm walls; the diaphragm walls were modelled as $1.2 \mathrm{~m}$ thick linear elastic plates with a short-term stiffness of $E=37 \mathrm{GPa}$. A further check was undertaken with a reduced stiffness of $50 \%$ of this value. Figure 5 shows the FE mesh adopted in the software model; the mesh was made of 735 triangular elements, with a refinement in the vicinity of the diaphragm wall. Only one half of the problem was modelled, owing to the symmetry alongside $\mathrm{AB}$.

When the shaft is excavated, the diaphragm walls have to withstand the external groundwater and lateral earth pressures, in addition to a variable $20 \mathrm{kPa}$ construction surcharge. The boundary conditions, drainage conditions and groundwater levels are shown in Figure 5. An elastic-plastic model with an interface strength reduction factor of 0.8 was used to define the interface between the soil and the diaphragm wall (Brinkgreve et al., 2009).

The SLS results of the effective stress analysis were used for comparison with the FO results.

\subsection{Hoop strain measurements}

\subsubsection{Dewatering effect}

The dewatering trial was carried out over 2 days in February 2012. The water table was lowered from $24 \mathrm{mbgl}$ to approximately $60 \mathrm{mbgl}$ on 1 February 2012. It was then allowed to rise back to $32 \mathrm{mbgl}$ until pumping was restarted at 8am on 2 February 2012. Pumping was then maintained, keeping the water table level constant at $70 \mathrm{mbgl}$ in wells W1 and W3 (Figure 1(b)). No dewatering was conducted from well $\mathrm{W} 2$; the well was used only to measure the water level. Two FO baseline datasets were recorded, on 9 and 26 January 2012; no dewatering works had been conducted during this period. Another FO dataset was recorded during the dewatering trial, while the water levels in wells $\mathrm{W} 1$ and W3 were maintained at $70 \mathrm{mbgl}$ on 2 February 2012.

Figure 6(a) plots the hoop strain changes for each panel between the two baseline datasets. Figure 6(b) plots the hoop strain changes between the dewatering and the second baseline dataset. The eight different markers correspond to the eight peaks/pretensioned sections in the circumferential direction (four on the soil face and four on the excavation face). For example, e1 is the highest measurement section on the excavation face, and s4 is the lowest/fourth peak on the soil face (Figure 2).

No change in hoop strain would be expected between the two baseline datasets. However, as shown in Figure 6(a), in panels P10 and P20 average compressional strains of approximately $100 \mu \varepsilon$ were measured, whereas panel P15 remained unchanged

\begin{tabular}{lccccccccc}
\hline Stratum & $\begin{array}{c}\text { Top level: } \\
\mathrm{mbgl}\end{array}$ & $\gamma: \mathrm{kN} / \mathrm{m}^{3}$ & $\mathrm{c}_{\mathrm{u}}: \mathrm{kPa}$ & $\begin{array}{c}\phi^{\prime}: \\
\text { degrees }\end{array}$ & $\mathrm{c}^{\prime}: \mathrm{kPa}$ & $K_{0}$ & $E_{\mathrm{u}}: \mathrm{kPa}$ & $\mathrm{E}^{\prime}: \mathrm{kPa}$ & $v$ \\
\hline Made ground & $0 \cdot 0$ & $18 \cdot 0$ & $\mathrm{n} / \mathrm{a}$ & $30 \cdot 0$ & $0 \cdot 0$ & $0 \cdot 5$ & $\mathrm{n} / \mathrm{a}$ & 5000 & $0 \cdot 30$ \\
Alluvium undrained & $6 \cdot 0$ & $16 \cdot 0$ & $20 \cdot 0$ & $\mathrm{n} / \mathrm{a}$ & $\mathrm{n} / \mathrm{a}$ & $0 \cdot 58$ & 6000 & $\mathrm{n} / \mathrm{a}$ & $0 \cdot 49$ \\
Alluvium drained & $6 \cdot 0$ & $16 \cdot 0$ & $\mathrm{n} / \mathrm{a}$ & $25 \cdot 0$ & $0 \cdot 0$ & $0 \cdot 58$ & $\mathrm{n} / \mathrm{a}$ & 4500 & $0 \cdot 30$ \\
River Terrace Deposits & $7 \cdot 0$ & $20 \cdot 0$ & $\mathrm{n} / \mathrm{a}$ & $38 \cdot 0$ & $0 \cdot 0$ & $0 \cdot 38$ & $\mathrm{n} / \mathrm{a}$ & 50000 & $0 \cdot 30$ \\
London Clay undrained & $11 \cdot 0$ & $20 \cdot 0$ & $115 \cdot 0$ & $\mathrm{n} / \mathrm{a}$ & $\mathrm{n} / \mathrm{a}$ & $1 \cdot 0$ & 92000 & $\mathrm{n} / \mathrm{a}$ & $0 \cdot 49$ \\
London Clay drained & $11 \cdot 0$ & $20 \cdot 0$ & $\mathrm{n} / \mathrm{a}$ & $25 \cdot 0$ & $0 \cdot 0$ & $1 \cdot 0$ & $\mathrm{n} / \mathrm{a}$ & 69000 & $0 \cdot 20$ \\
Lambeth Group Clay undrained & $17 \cdot 0$ & $20 \cdot 0$ & $160 \cdot 0$ & $\mathrm{n} / \mathrm{a}$ & $\mathrm{n} / \mathrm{a}$ & $1 \cdot 0$ & 128000 & $\mathrm{n} / \mathrm{a}$ & $0 \cdot 49$ \\
Lambeth Group Clay drained & $17 \cdot 0$ & $20 \cdot 0$ & $\mathrm{n} / \mathrm{a}$ & $27 \cdot 0$ & $0 \cdot 0$ & $1 \cdot 0$ & $\mathrm{n} / \mathrm{a}$ & 96000 & $0 \cdot 20$ \\
Lambeth Group Sand & $27 \cdot 0$ & $20 \cdot 0$ & $\mathrm{n} / \mathrm{a}$ & $40 \cdot 0$ & $0 \cdot 0$ & $1 \cdot 0$ & $\mathrm{n} / \mathrm{a}$ & 80000 & $0 \cdot 20$ \\
Thanet Sands & $33 \cdot 0$ & $21 \cdot 0$ & $\mathrm{n} / \mathrm{a}$ & $40 \cdot 0$ & $0 \cdot 0$ & $1 \cdot 0$ & $\mathrm{n} / \mathrm{a}$ & 225000 & $0 \cdot 30$ \\
Chalk & $47 \cdot 0$ & $19 \cdot 5$ & $\mathrm{n} / \mathrm{a}$ & $35 \cdot 0$ & $20 \cdot 0$ & $1 \cdot 0$ & $\mathrm{n} / \mathrm{a}$ & 1500000 & $0 \cdot 25$
\end{tabular}

Table 1. Geotechnical parameters used in the Plaxis effective stress analysis 


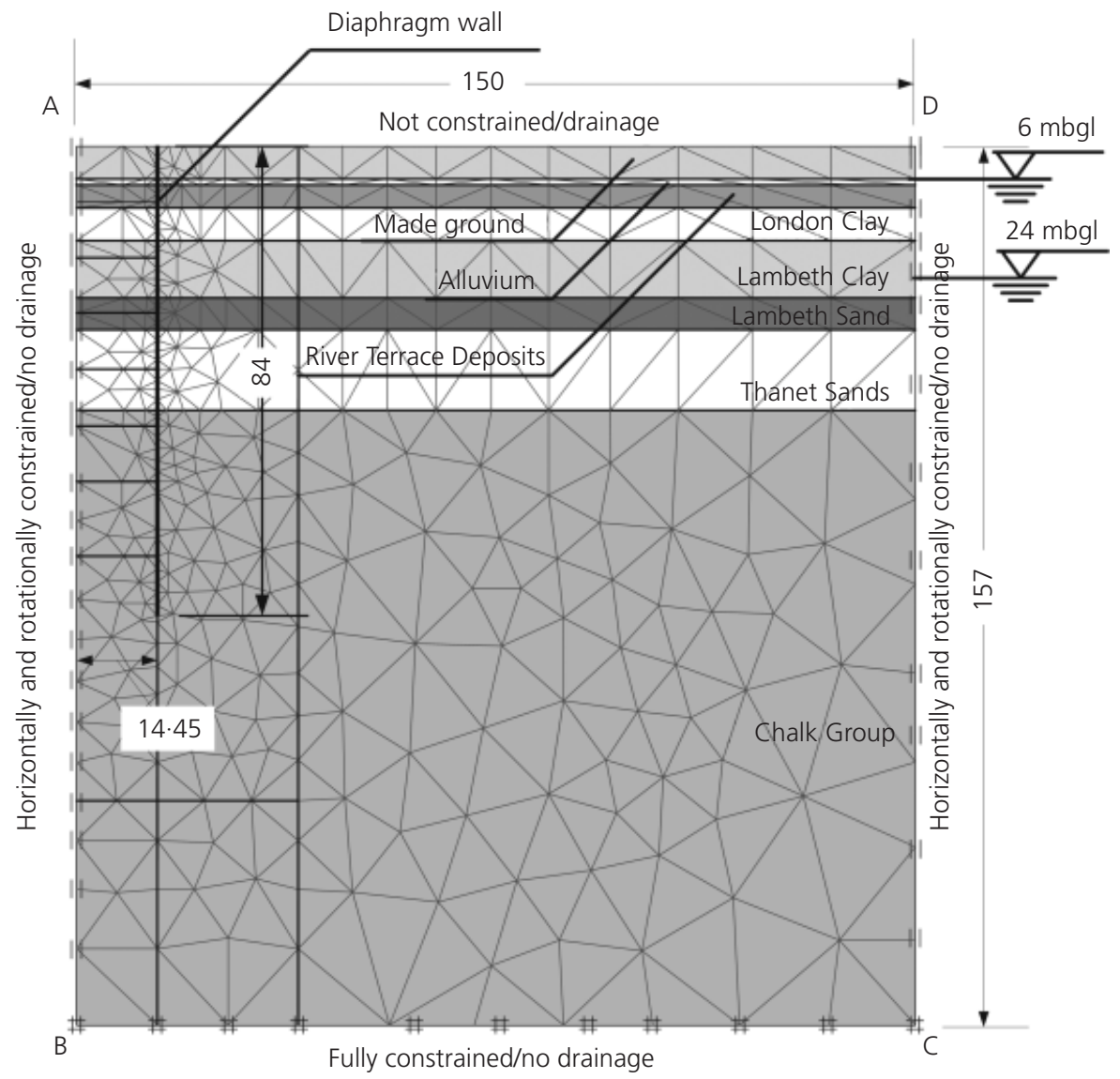

Figure 5. Plaxis model (dimensionless unless given above differently in $\mathrm{mm}$ )

on average, as would be expected. This could indicate that the resolution uncertainty in the FO measurement system is approximately $\pm 50 \mu \varepsilon$.

From Figure 6(b) it can be seen that during the dewatering stage panels P15 and P20 experienced compression between $100 \mu \varepsilon$ and $400 \mu \varepsilon$, while panel P10 experienced tensile strains of approximately $100 \mu \varepsilon$.

These measurements indicate that a three-dimensional deformation mechanism may have resulted as a consequence of different pumping operations of the three dewatering wells and the distance of the panels from the wells. Figure 6(b) shows that the water levels in wells $\mathrm{W} 1$ and $\mathrm{W} 3$ were both pumped to $70 \mathrm{mbgl}$ during the trial. No dewatering was conducted from well W2; this well was used to measure the water table drawdown at a distance from the well. These measurements (Figure 6(b)) show that the water levels inside the shaft did not fall uniformly; the water level in well $\mathrm{W} 2$, located $18 \mathrm{~m}$ away from wells $\mathrm{W} 1$ and $\mathrm{W} 3$, remained at $66 \mathrm{mbgl}$ - that is $4 \mathrm{~m}$ higher than the pumping level. When considering the well locations in comparison with the panels (Figure 1(b)), it is reasonable to assume that the water level on the wall at panel P10 was likely to be higher than the water level at panels P15 and P20. This may have caused the wall to deform non-uniformly, the sections with lower water pressures compressing and the sections with higher water pressure getting pushed away from the centre, and hence possibly exhibiting tensile strains. It should also be noted that the measurements for panel P10 were taken only around $2.5 \mathrm{~h}$ after pumping had started. Even though the water levels in the wells were lowered, the surrounding water pressure may have not been allowed sufficient time, and hence may have not reached steady-state conditions.

\subsubsection{Excavation effect}

Figure 7 shows the development of hoop strain with increasing excavation depth for panels P10 and P15. The markers stand for the different measurement peaks, and the grey shaded area indicates the depth of the HSC $(10 \mathrm{~m}$ interval centred around $46 \mathrm{mbgl}$ for panel P15 and around $60 \mathrm{mbgl}$ for panels P10 and P20). The dashed line represents the software model hoop strain predictions calculated by dividing the lateral wall deflections (at the depth of the hoop measurement sections) by the mean radius of the shaft $(14.45 \mathrm{~m})$.

The measurements from panels P10 and P20 (P20 measurements not presented) show a similar trend of hoop strain development 


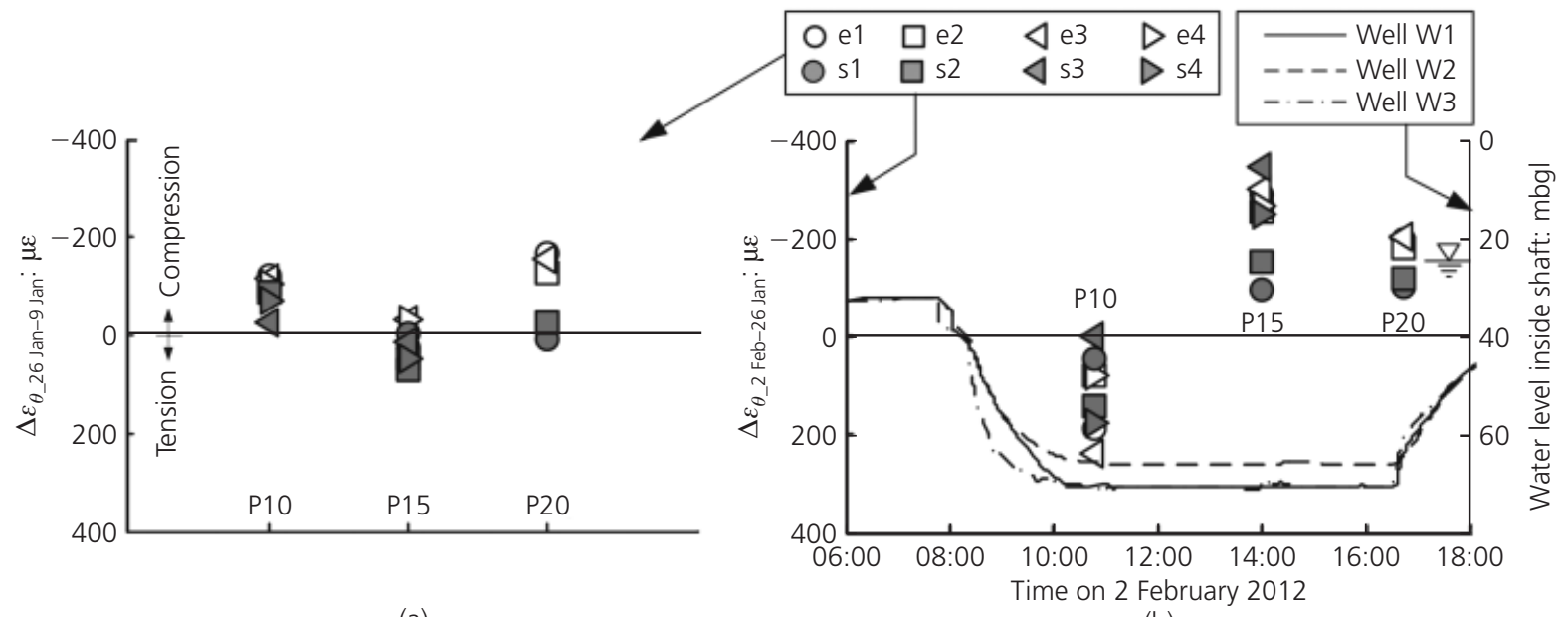

(a)

(b)

Figure 6. Incremental hoop strain: (a) between 9 and 26 January 2012; (b) between 26 January and 2 February 2012, and water levels in dewatering wells

with excavation: the compressional strain in the wall at $60 \mathrm{mbgl}$ increased during the early stages of the excavation. It further increased until an excavation depth of $35 \mathrm{mbgl}$. The hoop strain then stayed relatively constant, showing very little response until the excavation level reached the hoop cable level ( $60 \mathrm{mbgl})$, when it started increasing again. The average compressive hoop strain is approximately $500 \mu \varepsilon$ in panels P10 and P20 at an excavation depth of $71 \mathrm{mbgl}$. Compared with the software predictions, the measurements are significantly larger. The peak e3 readings of panel P10 are not taken into consideration, as they appear to be anomalously large, and do not match the other measurements. The cable might be located in a weak concrete batch or an air pocket.

The hoop strains measured in panel P15 did not follow the trends described above for panels P10 and P20. The measurements shown in Figure 7(b) indicate that the early stages of excavation had a small effect on the measured hoop strains. At the excavation level of $71 \mathrm{mbgl}$ only approximately $160 \mu \varepsilon$ of compressive hoop strain were measured, which is slightly below the software model predictions.

The hoop cables of panel P15 were attached at a higher level (between 41 and $51 \mathrm{mbgl}$ ) in comparison with panels P10 and P20 (between 55 and $65 \mathrm{mbgl}$ ). The comparisons of the FO measurements with the software model indicate that hoop strains at deeper levels in the chalk are larger than predicted (Figure 7(a), panels P10 and P20), and that hoop strains in the Thanet Sands are approximately as predicted (Figure 7(b), panel P15).

The hoop strain measurements can also be used to estimate the maximum radial wall movement. The largest average compressional hoop strain was approximately $500 \mu \varepsilon$ (panels P10 and P20 at an excavation depth of $71 \mathrm{mbgl}$ ); multiplying this value by the mean radius of the shaft $(14.45 \mathrm{~m})$ yields a radial wall movement of $7.2 \mathrm{~mm}$ to the inside of the shaft.

\subsubsection{Earth pressure calculation}

The final measurements taken at $71 \mathrm{mbgl}$ when the excavation depth exceeded the hoop cable depth can be used to backcalculate the earth pressure acting on the shaft. Assuming that the wall thickness, $t$, is small in comparison with the diameter, $D$, the classical circular arch equation can be used to calculate the incremental circumferential hoop stress

$$
\text { 3. } \Delta \sigma_{\theta}=\frac{-0 \cdot 5 D}{t}\left(\Delta p_{\mathrm{i}}-\Delta p_{\mathrm{o}}\right)
$$

where $\Delta p_{\mathrm{i}}$ and $\Delta p_{\mathrm{o}}$ are the incremental horizontal pressures between the baseline and the $71 \mathrm{mbgl}$ dataset, acting on the shaft from inside and outside respectively.

According to Hooke's law, the incremental circumferential hoop strain is

4. $\Delta \varepsilon_{\theta}=\frac{1}{E}\left(\Delta \sigma_{\theta}-v \Delta \sigma_{\mathrm{r}}\right)$

where $\Delta \sigma_{\mathrm{r}}$ is the change in the radial stress, $\Delta \sigma_{\theta}$ is the change in circumferential stress, $E$ is the Young's modulus and $v$ is the Poisson's ratio of the diaphragm wall. Under the thin wall approximation, it can be assumed that $\Delta \sigma_{\mathrm{r}}=0$.

The incremental internal pressure $\Delta p_{\mathrm{i}}$ changes from the total horizontal in situ earth pressure $\sigma_{\mathrm{h}}$ to 0 , and hence 


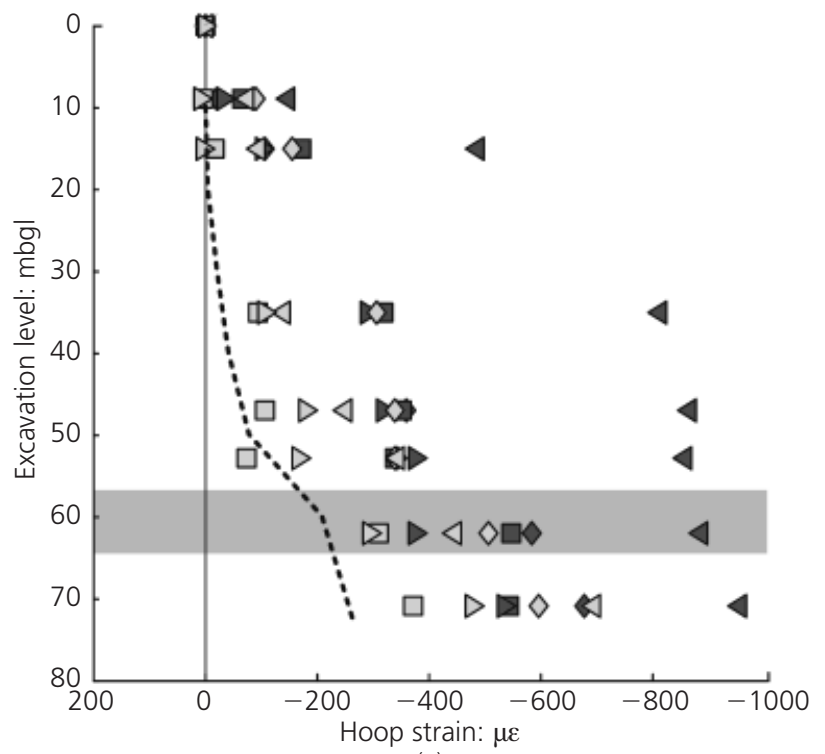

(a)

Figure 7. FO hoop strain development with excavation depth in comparison with Plaxis predictions. Measurements obtained from: (a) panel P10 (BOTDA); (b) panel P15 (BOTDR)

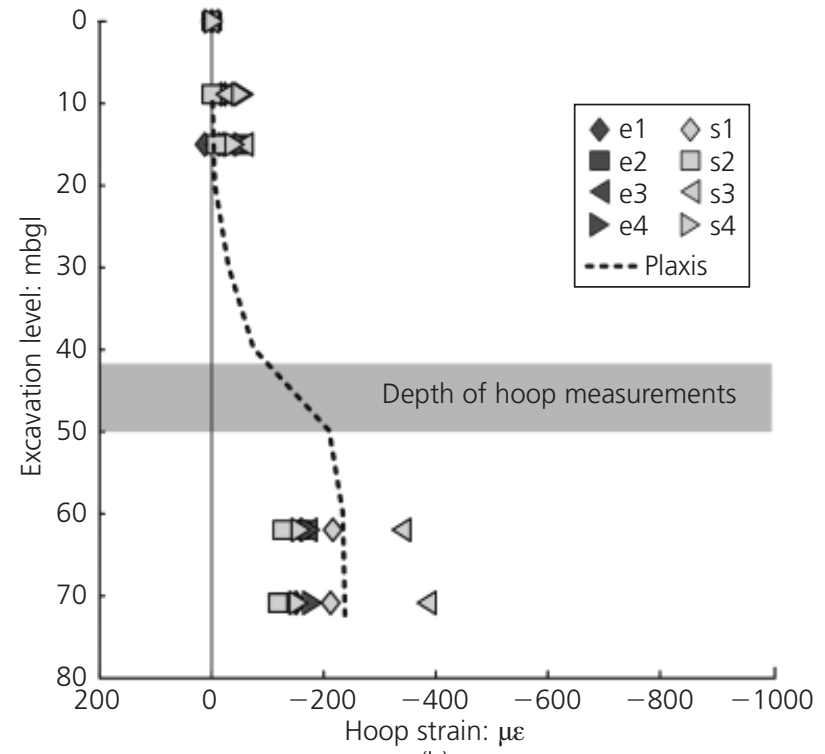

(b)

\section{5. $\Delta p_{\mathrm{i}}=-K_{0}\left(\sigma_{\mathrm{v}}-u_{0}\right)-u_{0}$}

where $K_{0}$ is the horizontal earth pressure coefficient at rest, $\sigma_{\mathrm{v}}$ is the total vertical in situ earth pressure, and $u_{0}$ is the initial pore water pressure.

Piezometers on site show a constant decrease of the lower aquifer of approximately $0.5 \mathrm{~m} /$ month from December 2011 to September 2012: therefore $\Delta p_{\mathrm{o}} \neq 0$. Assuming that $K_{0}$ and $\sigma_{\mathrm{v}}$ do not change by the water drawdown

$$
\text { 6. } \Delta p_{\mathrm{o}}=\left(1-K_{0}\right)\left(u_{1}-u_{0}\right)
$$

where $u_{1}$ is the pore water pressure when the $71 \mathrm{mbgl}$ measurements were taken.

This yields the following expression for $K_{0}$,

7. $K_{0}=\frac{2 E \Delta \varepsilon_{\theta} t / D-u_{1}}{\sigma_{\mathrm{v}}-u_{1}}$

For the earth pressure coefficient back-calculation the measurements of panels P10 and P20, which both show a similar trend, were used. Average compressive hoop strains of approximately $500 \mu \varepsilon$ were measured at an excavation level of $71 \mathrm{mbgl}$. With $t=1.2 \mathrm{~m}, E=37 \mathrm{GPa}, D=28.9 \mathrm{~m}, u_{1}=-316 \mathrm{kPa}$ and $\sigma_{\mathrm{v}}=-1192 \mathrm{kPa}$ this yields an earth pressure coefficient $K_{0}$ in the chalk of 1.4 , in comparison with 1.0 assumed in the design. It should, however, be noted that this equation is highly sensitive to the wall thickness, $t$, and the Young's modulus, $E$, of the wall. In reality the effective wall thickness is likely to be less than $1.2 \mathrm{~m}$, owing to the non-verticality of the panels. Site records show a verticality value (expressed as the ratio of the horizontal offset at the bottom of the wall to the vertical depth of the wall) of 1:400. At a depth of $60 \mathrm{~m}$, where the hoop strains were measured, this is equivalent to a $0.3 \mathrm{~m}$ reduction in wall thickness $t$. With an effective wall thickness of $t^{\prime}=0.9 \mathrm{~m}$, Equation 7 yields $K_{0}=1 \cdot 0$; if additionally the Young's modulus is reduced by $20 \%$, $K_{0}$ is only $0 \cdot 7$.

\subsection{Bending strain}

Selected bending strain results obtained during the shaft excavation are shown in Figure 8. The plots show the incremental curvature change between different construction stages, over the depth of the wall. The label above each figure (e.g. $\Delta \kappa_{71-62}$ ) specifies the two excavation levels (here $71 \mathrm{mbgl}$ and $62 \mathrm{mbgl}$ ) between which the curvature increment is taken. A positive value indicates tension on the soil face and compression on the excavation face. The data for panel P10 were not reliable, as it is believed that the cable snapped during installation, and is therefore omitted.

The three panels were also equipped with inclinometers (Figure 1(b)); the inclination data were interpolated, filtered and differentiated over depth to obtain the differential curvature from this independent device. The results from panels P10 and P20 are also displayed in Figure 8; the inclinometer casing of panel P15 was blocked and could not be used. 
The software model predictions are also plotted in the figures, where the curvature was obtained by dividing the bending moment results by the flexural rigidity of the wall, EI. The software bending moments, however, were only available at $10 \mathrm{~m}$ excavation intervals up to a depth of $60 \mathrm{~m}$ and then at a depth of $73 \mathrm{~m}$, whereas the FO measurements were recorded at different excavation depths. Therefore it was necessary to interpolate between the sets of the numerical analysis results to be able to compare FO measurements with the software model results.

The FO measurements and inclinometer data in Figure 8 clearly show bending around the excavation level, with bending towards the shaft below the excavation level and away from the shaft above the excavation level. The data from the two independent devices in panel P20 correlated well, and the inclinometer data of panel P10 also show similar magnitudes to the FO measurements.

Comparing the measured incremental curvature with the software model curvature predictions, it can be seen that the incremental curvatures exceeded the predictions significantly (Figure 8).

\section{Discussion}

Both the hoop and the bending strain measurements exceeded the software model predictions in the chalk. A combination of several factors may have resulted in this.

The wall thickness in the software model was assumed to be $1.2 \mathrm{~m}$, which did not account for any reduction caused by the non-verticality of the panels or the concrete scraped off during excavation. With effective wall thicknesses reducing with depth, the software analysis may yield higher curvatures. Additionally, there is some uncertainty in the Young's modulus where the short-term value of $37 \mathrm{GPa}$ was used, which may have underpredicted both the hoop and the bending strain.

The software model analysis conducted during the design stage did not consider the complex three-dimensional problem of the diaphragm wall installation. In reality, the panel construction sequence and the associated horizontal and vertical arching effects (Richards et al., 2006) could have influenced the FO measurements. Further investigations are being carried out.

Another point of uncertainty is the chalk stiffness. It is highly non-linear, with lower-bound Young's modulus values varying between $300 \mathrm{MPa}$ and $500 \mathrm{MPa}$ for axial strains between $1 \%$ and $0.01 \%$ respectively, and upper-bound values between $1500 \mathrm{MPa}$ (at $1 \%$ axial strain) and $4300 \mathrm{MPa}$ (at $0.01 \%$ axial strain). The software design adopted a value of $1500 \mathrm{MPa}$, which falls in between the upper- and lower-bound values for an axial strain of $0 \cdot 1 \%$. The analysis does not consider any degradation effects depending on the actual strain. If the chalk had a lower stiffness than assumed, this would allow the $K_{0}$ condition to drop less rapidly towards the active $K_{\mathrm{a}}$ value, even with wall movement, and therefore produce higher lateral earth pressures.

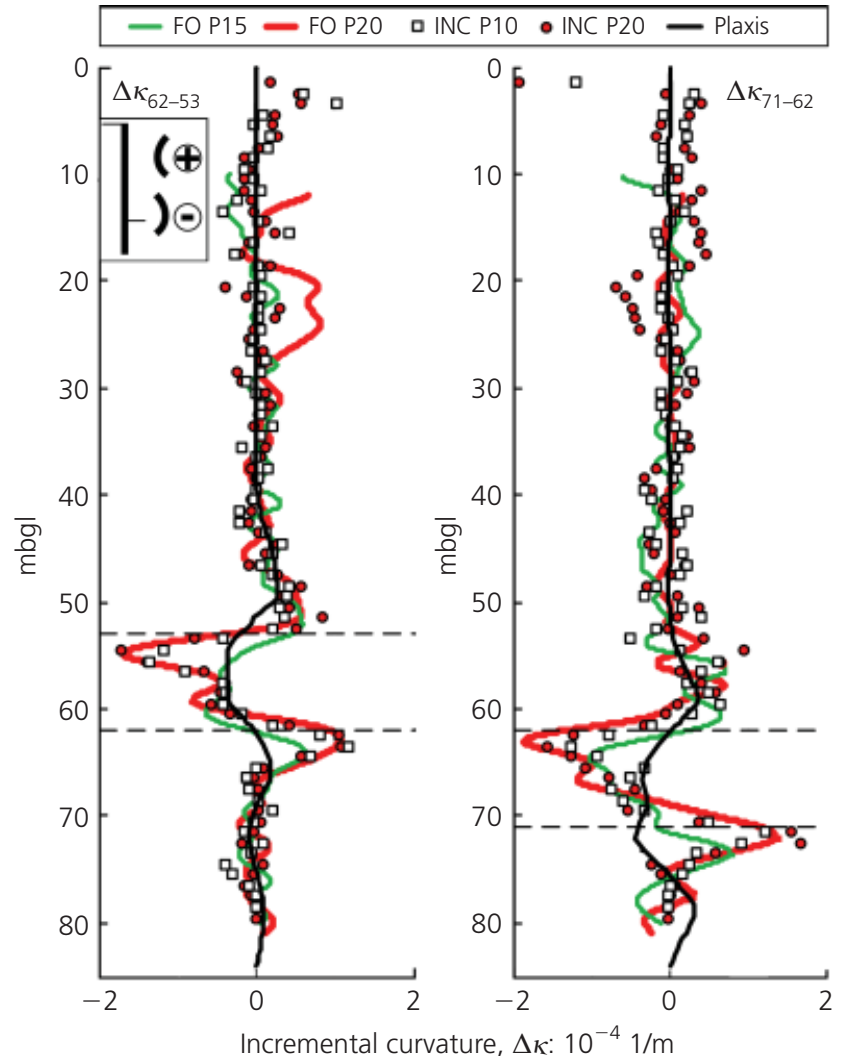

(a)

(b)

Figure 8. Incremental curvature between different excavation levels: (a) $\Delta \kappa_{62-53}$; (b) $\Delta \kappa_{71-62}$

In addition, the software simulation modelled the wall as an isotropic material with the same stiffness in the vertical as in the circumferential direction, which is probably not the case, owing to the discontinuity of diaphragm walls in circumferential direction (Cabarkapa et al., 2003; Zdravkovic et al., 2005). The presence of joints between the panels could have caused the larger hoop strains and, along with the smaller hoop stiffness, induced more bending of the panels. Further analysis is being carried out to investigate this.

\section{Conclusion}

The AM shaft case study presented in this paper demonstrated how fibre optic sensors were successfully installed in three $84 \mathrm{~m}$ long diaphragm walls with minimal disruption to the wall installation process. The bending and hoop strains in the circular shaft were measured and compared with the design predictions at various stages of construction, including a dewatering trial followed by the shaft excavation.

The results suggest that asymmetric hoop strains developed in the panels during the dewatering trial. The hoop and bending strain measurements during shaft excavation were larger than the design predictions; this may have been caused by non-verticality of the 
walls. Owing to a decreasing effective wall thickness with depth, the structure may be less stiff than assumed in design. Other reasons may be a lower ground stiffness (principally the chalk) than adopted in the analysis and/or an anisotropic wall with lower circumferential stiffness due to the discontinuity of the diaphragm wall in the joints.

The FO monitoring of the $84 \mathrm{~m}$ deep shaft has thrown new light on the detailed performance of the shaft. In particular, it has elucidated the magnitude of bending strain and circumferential hoop strain induced in the shaft walls. This provides valuable information for the design of future deep shafts in the London area.

\section{Acknowledgements}

The authors would like to thank Thames Water Ltd and the Lee Tunnel Project Management Team for making the field study possible in the first place; the support from Roger Mitchell and Peter Jewell is greatly appreciated. The assistance and help from the contractor MVB JV (a joint venture of Morgan Sindall, Vinci Construction Grands Projets and Bachy Soletanche) were essential for the successful accomplishment of the study; special thanks go to Ba Dan Nguyen, Jean-Christophe Galan, Julian Gatward and Sivilay Sayavong. The cooperation and support of the site operatives is also highly appreciated. Without the invaluable help of the Cambridge FO team, Fei Wang, Gue Chang Ye, Koson Janmonta, Njemile Faustin, Peter Knott and Seda Torisu, this field study would not have been possible.

\section{REFERENCES}

Brinkgreve RBJ, Broere W and Waterman D (2009) PLAXIS 2D,

Finite element code for soil and rock analyses, users'

manual, Version 9.0. Plaxis, Delft, the Netherlands.
BSI (2004) BS EN 1997-1: 2004. National Annex A: Partial and correlation factors for ultimate limit states and recommended values. BSI, London, UK.

Butterworth S (1930) On the theory of filter amplifiers. Wireless Engineer (also called Experimental Wireless and the Wireless Engineer) 7(October): 536-541.

Cabarkapa Z, Milligan GWE, Menkiti CO, Murphy J and Potts DM (2003) Design and performance of a large diameter shaft in Dublin boulder Clay. In Proceedings of Foundations: Innovations, Observations, Design and Practice (Newson TA (ed.)). Thomas Telford, London, UK, pp. 175-185.

Clayton CRI (1990) The mechanical properties of the chalk. Proceedings of the International Chalk Symposium. Thomas Telford, London, UK, pp. 213-232.

Mohamad H, Bennet P, Soga K, Mair RJ and Bowers K (2010) Behaviour of an old masonry tunnel due to tunnellinginduced ground settlement. Géotechnique 60(12): 927-938.

Mohamad H (2008) Distributed Optical Fibre Strain Sensing of Geotechnical Structures. PhD thesis, Department of Engineering, Cambridge University, UK.

Omnisens (2013) DITEST-STA-R Series: Fiber optic distributed temperature \& strain monitoring system. Omnisens, Morges, Switzerland. See http://www.opticalfibersensors.org/website/ optical-fiber-sensors/assets/files/productdownloads/dt-diteststa-r.pdf (accessed 11/03/2013).

Richards DJ, Clark J and Powrie W (2006) Installation effects of a bored pile wall in overconsolidated clay. Géotechnique 56(6): 411-425.

Yokogawa (2005) AQ8603 Optical Fiber Strain Analyzer. Yokogawa, Tokyo, Japan. See http://tmi.yokogawa.com/files/ uploaded/buaq8603_00e.pdf (accessed 11/03/2013).

Zdravkovic L, Potts DM and St John HD (2005) Modelling of a $3 \mathrm{D}$ excavation in finite element analysis. Géotechnique 55(7): 497-513.

\footnotetext{
WHAT DO YOU THINK?

To discuss this paper, please email up to 500 words to the editor at journals@ice.org.uk. Your contribution will be forwarded to the author(s) for a reply and, if considered appropriate by the editorial panel, will be published as a discussion in a future issue of the journal.

Proceedings journals rely entirely on contributions sent in by civil engineering professionals, academics and students. Papers should be 2000-5000 words long (briefing papers should be 1000-2000 words long), with adequate illustrations and references. You can submit your paper online via www.icevirtuallibrary.com/content/journals, where you will also find detailed author guidelines.
} 